\title{
Healthcare startups and ecosystems: Insights from an emerging market economy
}

\author{
Kanchan Mukherjee \\ Professor \\ Centre for Health Policy, Planning and Management \\ School of Health Systems Studies \\ TISS, Mumbai, India \\ Web page: https://www.tiss.edu/view/9/employee/kanchan-mukherjee/
}

\section{Highlights}

- This study addresses an important research gap in entrepreneurship literature i.e. healthcare startups and policies.

- Provides insights into the healthcare startup landscape and startup ecosystem in an emerging market economy i.e. India.

- Creates a convergent stream framework (CSF) to help conceptualize gaps across startup lifecycle which has relevance for researchers, entrepreneurs and policy makers globally.

- Highlights the need for a universal coherent, responsive and inclusive ecosystem for converting a crisis into an opportunity for achieving sustainable development goals. 


\section{Introduction}

Entrepreneurship is very closely associated with economic development by creating wealth, employment, products and services, and generating taxes (Carree and Thurik, 1998 and 2002; Reynolds et al., 2002; Awasthi et al., 2006). The growth of startups globally is a reflection of this growth in entrepreneurship worldwide. Health is one of the areas where the rate of progress of science and technology in the last century has been most remarkable. At the same time, it has been greatly uneven across and within countries and disease areas and the COVID-19 pandemic has exposed the vulnerabilities of healthcare system globally. In this context, innovation and entrepreneurship in the healthcare sector is helping address these challenges, supplementing the efforts of governments and bridging the gap between actual and potential performance of healthcare systems.

The global healthcare industry was worth USD 8.45 trillion prior to the COVID-19 pandemic and global healthcare spending is expected to reach USD 10 trillion by 2022 (Stasha, 2021) inspite of a decrease in spending by $2.6 \%$ in 2020 due to the COVID-19 pandemic (Deloitte, 2021). This decrease in healthcare spending, which happened due to lockdown and social distancing measures resulted in greater use of virtual platforms and technology for health monitoring. The pandemic thus reflects two sides of the same coin-crisis and opportunity. While straining the healthcare sector infrastructure, human and financial resources and exposing social inequalities; it also acted as a catalyst for change across the ecosystem and stimulated innovation and entrepreneurship to deal with the health crisis. Favoured by policy push, the pandemic has resulted in creation of many startups focused on addressing the challenges faced by the healthcare sector. However, despite the importance of the healthcare startup sector in terms of revenue and employment as well as a policy priority, there is very little analysis on healthcare startups and its relevance for policy. Hence, this paper proposes 
to address this important gap in literature, which will be useful for researchers, entrepreneurs and policy makers.

India has been selected as a case study based on its economic, epidemiological and entrepreneurship profile. Economically, India belongs to an emerging market economy and an important investment destination globally. Epidemiologically, it has been severely affected by the COVID-19 pandemic but has also shown improvement in its global entrepreneurship rankings and is currently the third largest startup economy in the world after the USA and UK (Global innovation index, 2020). This study is also important in terms of its policy timing since India is currently drafting a new science, technology and innovation policy (STIP) to replace the existing policy, while the startup policy has completed five years and has attained a maturity conducive for a review. In the above context, the study aims to answer the following research questions (RQ):

RQ 1. What is the existing healthcare startup landscape and startup ecosystem in India?

RQ 2. What are the existing gaps in the healthcare startup lifecycle?

RQ 3. What policy measures can be recommended to address these gaps?

RQ 4. What are the learnings and future research questions for startup policies globally? Based on the findings, the study creates a conceptual framework for policy analysis across the startup life cycle which can be tested, modified and applied to other country contexts.

\section{Material and Methods}

This study was based on analysis of open access data available in the public domain. For RQ

1, documents published on startups, entrepreneurship and innovation reviews and reports were analysed to understand the existing landscape of healthcare startups in India. The startup India portal website (www.startupindia.gov.in) was used to identify existing startups, their sub-sectors and stages, i.e., ideation, validation, early traction and scaling. Startups listed under the healthcare and life sciences sector were analysed in-depth for the quantitative part 
of this study. A comparative analysis was performed across the sub-sectors and stages to provide insights into the current status.

For RQ 2, perspectives from experts [Key Informants (KI)], which were available online as part of the STIP consultative process, were analyzed to obtain qualitative insights (Science Policy Forum, 2020). The consultations included 16 different domain areas of startups of which seven, which were relevant to healthcare startups and ecosystem were selected for this study. The seven domains selected included health; innovation and entrepreneurship; governance and system interconnectedness; strategic, disruptive and futuristic technology; access to knowledge

and resources; financing, equity and inclusion; policy governance and programme linkages. A thematic analysis was done in each of these seven domains to identify core themes emerging across the startup life cycle with the focus on gaps and possible solutions. In all, perspectives of $28 \mathrm{KIs}$, who are experts in the field of health, finance, startups, incubators and policy making affiliated with academia, industry and government, were analysed in this study. This thematic analysis was then used to create a conceptual framework which would be useful for researchers, practitioners and policy makers to identify gaps and recommend or implement solutions. Data triangulation of the quantitative and qualitative analysis was done to draw insights and conclusions.

\section{Results}

\subsection{The context-Indian healthcare sector.}

Healthcare is one of the largest and fastest growing sectors (CAGR 22.9\%) in India both in terms of revenue and employment (fourth largest employer) and is projected to reach $\$ 372$ billion by 2022 (IBEF, 2021). The Government of India (GoI) is involved in facilitating innovation through favourable policies and entrepreneurship programmes. Investments in health technology startups increased by $45 \%$ and the biotechnology industry comprises more than 2700 biotech startups and is estimated to reach 10,000 by 2024 (IBEF, 2021). By 2050, 
the population in India is expected to reach 1.7 billion people and elderly population is expected to grow to $19 \%$ (from $8 \%$ in 2015) (UNFPA, 2017) adding to the increasing burden of Non Communicable Diseases (NCDs). This demographic and epidemiological profile change will demand further evolution of the Indian healthcare sector.

To address this demand, India is leapfrogging the use of technology innovations such as mobile health devices, telemedicine strategies, low cost diagnostics, which could reduce the burden on the healthcare system while continuing to boost healthier lives, reducing disabilities and increasing life expectancy. The GoI has plans to further develop India into a global healthcare hub by leveraging its relatively lower-priced treatment options (PWC, 2018). Hence, policies encouraging these initiatives have been on the ministerial agenda of both the state and federal/union government.

\subsection{Startup policy}

In order to build and sustain entrepreneurship at the start up level a number of policy initiatives were taken, starting with the 'Make in India' campaign in 2014. This initiative was aimed at encouraging foreign investment and increasing domestic manufacturing capacity. The two key steps initiated in this policy initiative were to increase the foreign direct investments (FDI) limits for most of the sectors and protection of intellectual property rights of entrepreneurs, innovators and creators. This was followed in 2015 with the 'Standup India' initiative with the focus to increase bank funding to startups and promote entrepreneurship among women and addressing marginalized sections of Indian society. This was followed closely by the 'Digital India' initiative with the aim to connect rural India by digital infrastructure. These above policy initiatives set the stage for the creation of the startup policy, which was officially launched on January 2016 by the Department for Industrial Policy and Promotion (DIPP), now known as Department for Promotion of Industry and Internal Trade (DPIIT), and located within the Ministry of Commerce and Industry. 


\subsection{The definition of a startup}

There is no universal definition of startup and it varies across different countries. DPIIT defines a startup using the parameters of location, time, annual turnover, innovation and scalability. Using these parameters, a startup is currently defined as an entity registered or incorporated in India established for not more than 10 years, with annual turnover not exceeding INR 1 billion (approximately 14 million USD) in any preceding financial year, and working towards innovation, development or improvement of products or processes or services and is a scalable business model with a high potential of employment generation or wealth creation. It excludes entities formed by splitting up, or reconstruction, of a business already in existence (Startup India, 2020). The DPIIT operationalized the startup India hub in April 2016, which is India's largest entrepreneurship portal and allows startup founders to network with mentors and investors, access relevant tools and resources and participate in programmes and challenges.

\subsection{Analysis of extant literature on healthcare startups and startup ecosystems}

According to National Association of Software and Services Companies (NASSCOM) report, healthcare sector startups are among the top four startup sectors in India, contributing to $8 \%$ of all startups in 2018, and have shown a high growth rate in the last five years (NASSCOM, 2018). The distribution of value chain components in Indian healthcare sector startups shows a large share in healthcare treatment (58\%) and diagnostics (20\%), and less share in prevention (10\%) (Bertelsmann Stiftung, 2018). Key trends and business models emerging in the healthcare startups in India include diagnostics, naturopathy and wellness centers, digital health records, hospital information systems, mobile healthcare and innovative public-private partnership (PPP) models. However, the scope of these individual startups is usually very narrow which makes the startup space highly fragmented. 
The variety of services, products and offerings makes healthcare one of the most challenging aspects of the economy. These startups are using artificial intelligence (AI), machine learning (ML) and other modern technology to improve access, affordability and quality of healthcare (Soni, 2019). Research indicates that India could save up to $\$ 10$ billion in 2025 , by using telemedicine instead of in-person doctor consultations (Mckinsey, 2010). According to a 2018 Research and Markets report, India currently has over 850,000 independent pharmacy retail stores but they are able to meet only $60 \%$ of the total demand. This highlights the huge untapped market opportunity for e-pharmacy startups in India. The report estimated the online pharmacy space to grow at a Compounded Annual Growth Rate (CAGR) of over 20\%, to reach the $\$ 3$ billion mark by 2024 . Women's issues are also specifically addressed through personal health tracking apps, which help women track periods and pregnancy.

\subsection{Startup ecosystem}

The World Economic Forum (2015) has expanded the notion of innovation beyond technological innovation to the notion of 'ecosystem' to include dynamic collaborative networks of individuals and organizations with an innovative objective (Smorodinskaya, 2017). The startup ecosystem in India can be divided into three broad domains through which individuals and organizations interact with each other. These three domains include finance, regulation and technology transfer. As on date (May 21, 2021), there are twenty funding agencies, nine regulatory bodies and twenty-two technology transfer entities which are part of the startup ecosystem, which makes it a complex ecosystem with startups having to negotiate multiple regulatory and policy frameworks.

\subsection{Current status of India's healthcare startups: Evidence from startup India portal}

The startup India portal classifies a startup into four stages - ideation, validation, early traction and scaling. As on May 7, 2021, there were 48,297 startups registered with DPIIT on this portal with $23,443(48.5 \%)$ in early traction/scaling stage. Of these 48,297 startups, 
Information Technology (IT) services and healthcare and life sciences were the top two startup sectors in terms of numbers. Startups in the healthcare and life sciences sector constituted $8.7 \%$ of all startups in this portal which is an increase of $0.7 \%$ from the 2018 NASSCOM figures. Figure 1 shows the various stages of these startups.

Figure 1. Stage distribution of healthcare startups.

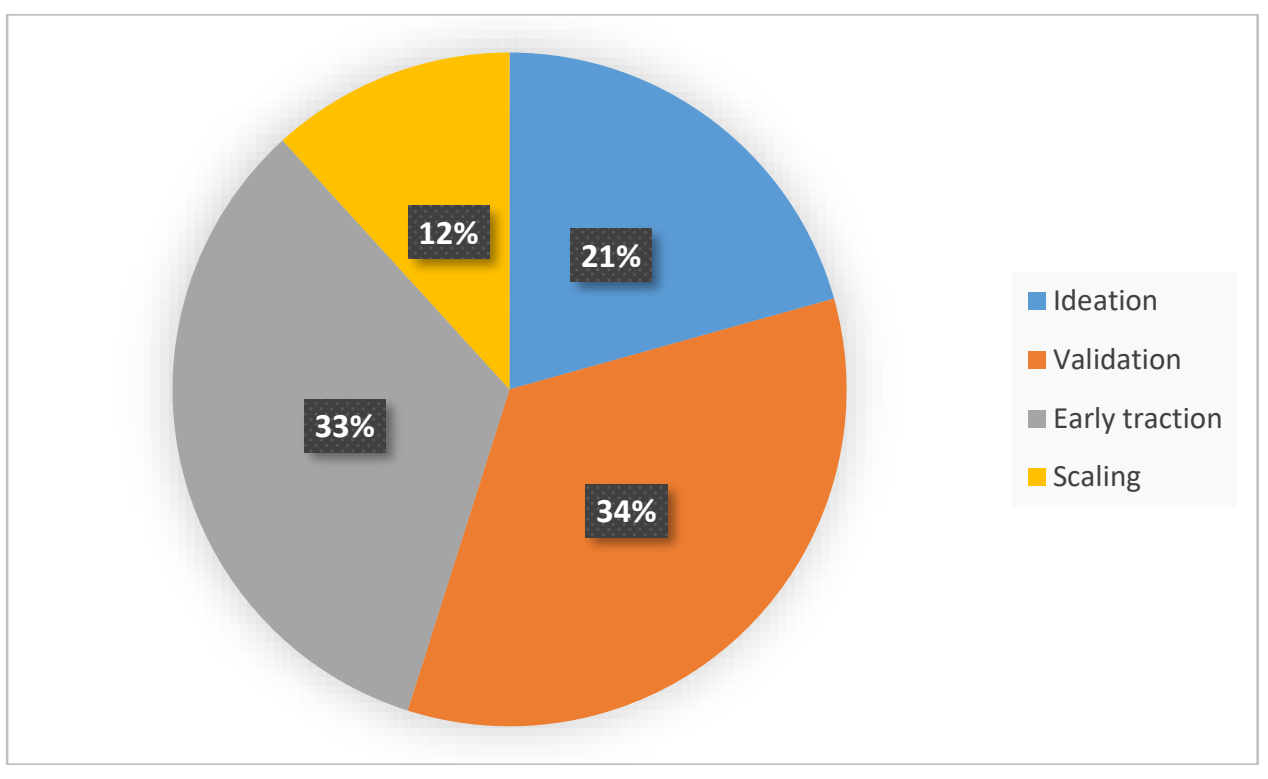

The majority (55\%) of healthcare startups are in the ideation or validation stage, which implies the existence of an idea for the product or the service that the startup will deal in (ideation); or a minimum value product (MVP) has been developed for the market (validation). Meanwhile, $45 \%$ of the these are at a stage where the startup has acquired customers and started generating revenue (early traction) or the startup has stabilized and started generating profits (scaling). Figure 2 shows the distribution of different sub-sectors within this healthcare sector as classified by the startup portal. Health and wellness, healthcare services and medical devices contribute to around $60 \%$ of the startups in this sector. 
Figure 2. Distribution of sub-sectors among healthcare startups.

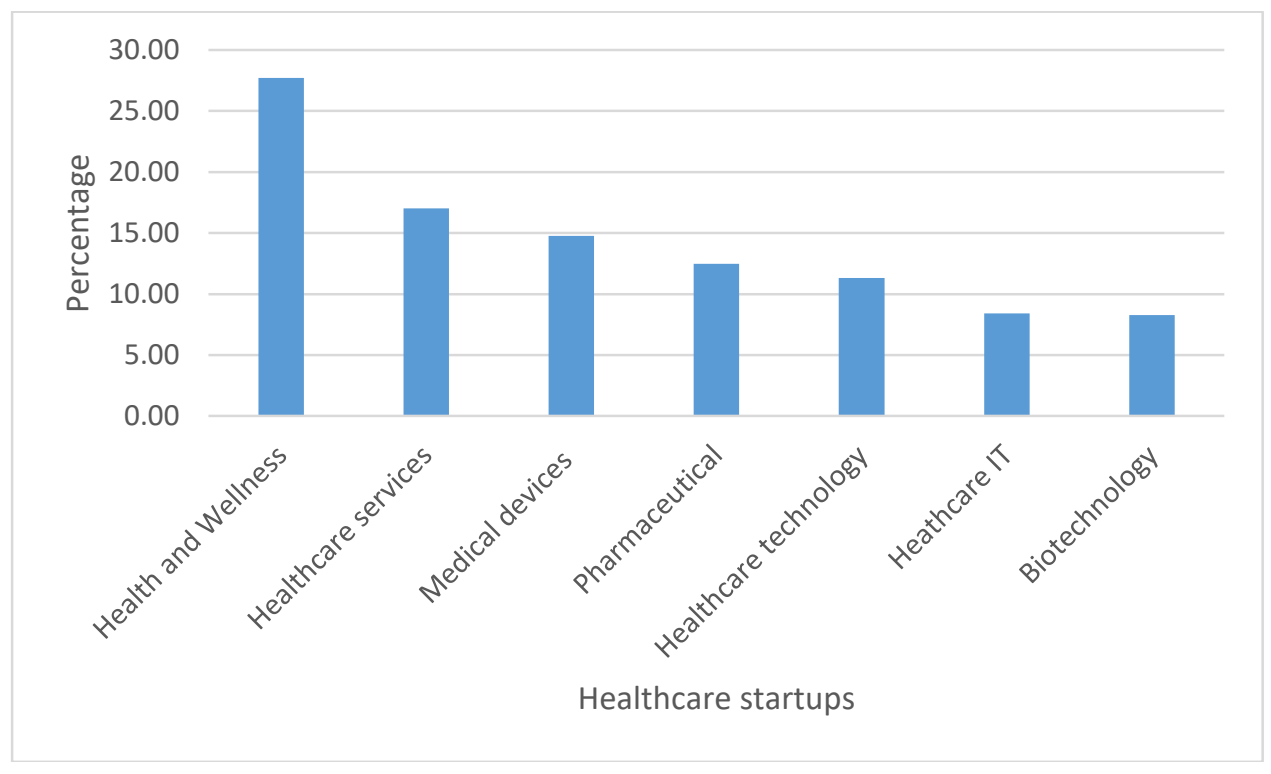

For this study, the startups were operationally classified into early stage and late stage startups. Early stage startups included those in the ideation and validation stage, while late stage startups included those in the early traction and scaling stages. As shown in Table 1 (below), the maximum number of startups are in the health and wellness sub-sector and this subsector also has the early: late stage ratio of less than one. This indicates that health and wellness startups are not only the most popular startups among entrepreneurs but also have good market penetration. In addition, healthcare services and healthcare IT startups have the ratio very close to one, indicating that these sub sector startups are more mature and established as compared to the other sub sectors. Biotechnology and medical devices startups have the worst ratio relatively, which probably reflects the longer time period required for such products to enter the market and stabilize. 
Table 1. Stage distribution of healthcare startups across each sub-sector (As on May 7, 2021)

\begin{tabular}{|c|c|c|c|c|c|c|c|c|}
\hline $\begin{array}{c}\text { Startup } \\
\text { sub-sectors }\end{array}$ & $\begin{array}{c}\text { No. of } \\
\text { startups }\end{array}$ & Ideation & Validation & $\begin{array}{c}\text { Early } \\
\text { traction }\end{array}$ & Scaling & $\begin{array}{l}\text { Early } \\
\text { stage }\end{array}$ & $\begin{array}{l}\text { Late } \\
\text { stage }\end{array}$ & $\begin{array}{c}\text { Ratio (early } \\
\text { stage: late } \\
\text { stage) }\end{array}$ \\
\hline $\begin{array}{l}\text { Health and } \\
\text { Wellness }\end{array}$ & 1162 & 219 & 335 & 451 & 157 & 554 & 608 & 0.91 \\
\hline $\begin{array}{c}\text { Healthcare } \\
\text { services }\end{array}$ & 714 & 128 & 223 & 260 & 103 & 351 & 363 & 0.97 \\
\hline $\begin{array}{c}\text { Medical } \\
\text { devices }\end{array}$ & 619 & 163 & 246 & 152 & 58 & 409 & 210 & 1.95 \\
\hline Pharmaceutical & 523 & 119 & 194 & 143 & 67 & 313 & 210 & 1.49 \\
\hline $\begin{array}{l}\text { Healthcare } \\
\text { technology }\end{array}$ & 474 & 79 & 197 & 165 & 33 & 276 & 198 & 1.39 \\
\hline Healthcare IT & 353 & 55 & 122 & 134 & 42 & 177 & 176 & 1.01 \\
\hline Biotechnology & 347 & 103 & 118 & 93 & 33 & 221 & 126 & 1.75 \\
\hline Total & 4192 & 866 & 1435 & 1398 & 493 & 2301 & 1891 & 1.2 \\
\hline
\end{tabular}

With the coming of the pandemic in India, there has been a number of initiatives to encourage and fast tract startups innovating on affordable and effective solutions addressing the dimensions of care associated with COVID-19 (Mukherjee, 2021). Policy response to the startup sector in India during COVID-19 is similar to the global response reported in literature which included extension of existing support programmes, tax relief extension, cut in loan interest rates etc. (Kuckertz et al, 2020). 


\subsection{Evidence from the STIP consultation process}

Thematic analysis of perspectives from the expert KIs involved in the STIP consultation process focused on understanding progress, gaps and possible solutions in the healthcare startup sector. The analysis revealed three dominant or core themes as gaps across the startup lifecycle and its ecosystem. These were awareness and access to information, mentoring and networking, and funding. Table 2 provides the key thematic areas identified as gaps, and their relative intensity and distribution across the startup lifecycle.

Table 2. Thematic gaps across the startup lifecycle with their relative weights

\begin{tabular}{|c|c|c|c|}
\hline $\begin{array}{c}\text { Startup } \\
\text { stages }\end{array}$ & Creation & Emergence & Diffusion/Disruption \\
\hline Thematic gaps & & & \\
\hline $\begin{array}{c}\text { Awareness and } \\
\text { Access to information }\end{array}$ & +++ & & \\
\hline $\begin{array}{c}\text { Mentoring and Networking } \\
\text { Funding (Amount and } \\
\text { Timeliness) }\end{array}$ & +++ & ++ & ++ \\
\hline
\end{tabular}

Awareness and access to information along with funding were identified as important gaps in the early stage of the startup lifecycle. Funding along with mentoring/networking emerged as a key issue during the emerging phase, while mentoring/networking continued to be a gap in the diffusion/disruption phase of the startup.

In addition to the above core themes across the startup life cycle, there were some important insights for the startup ecosystem. Almost all the KIs mentioned that there were multiple sources and types of information regarding startups available at multiple places, which resulted in confusion among those interested in initiating a startup. The link between academia and industry was also stated to be weak, and the roles of mentoring and networking 
were emphasized. Funding availability, especially in the early stage, was mentioned as a major drawback, which in turn affected long-term motivation of the entrepreneur and innovator. Specific to healthcare, the role of startups in improving primary healthcare, addressing NCDs, crowd sourcing of data, contact tracing, pharmacovigilance, knowledge sharing platforms, data acquisition and analysis by frontline workers were emphasized.

\section{Discussion}

Startups are a reflection of the extent of innovation and entrepreneurship spirit in a society. In the five years (2016-20) of the startup India initiative, significant improvements have been made in the entrepreneurship and innovation sector in India. India's overall ranking in the Global Innovation Index improved significantly from 66 to 48, ease of starting a business ranking improved moderately from 77 to 63 and university-industry research collaboration ranking improved marginally from 49 to 45 . India has performed best in knowledge and technology outputs, and weakest in infrastructure sector. Some other weaknesses identified in Global Entrepreneurship Monitoring (GEM) report include education, tertiary inbound mobility, environmental performance and low female formal employment. The findings of this study reveal similar findings in terms of growth of startups especially in IT and healthcare and life sciences. This study also reveals a gap in translation between knowledge economy and commercial economy as evident from the weak university-industry network and the gap in mentoring and networking.

Entrepreneurship is infrequently considered as a career option in India, given the historical societal preferences of salaried jobs and careers. This social culture needs to be addressed by policy options like reducing barriers and facilitating entrepreneurship efforts, in order to encourage entrepreneurship as a career. Risk of failure has also been identified as a reason for reluctance in pursuing opportunities for initiating a startup. This highlights the role of soft policy options facilitating early mentoring and networking in the startup process to provide and 
sustain motivation, opportunity and skills. However, this study finds that even after five years of the startup policy implementation this remains a gap which needs to be addressed. Financing emerged as an important obstacle especially in the critical early phase and is a major contributor to startup exit with over $75 \%$ of entrepreneurship exiting the market in India due to lack of profitability or financial issues (GEM report, 2018). Inspite of the presence of a score of funding agencies in the ecosystem, angel investors and equity financing are key drivers of startup financing in India with limited traction of government policies (Ghosh, 2020).

Based on the findings of this study, the following specific recommendations are proposed. Development of an integrated online platform to provide all startup/entrepreneurship/innovation-related information resources from different ministries and departments at a common place is essential. Currently, there are eight GoI ministries (and their internal departments) as well the federal government think tank -National Institute of Transforming India (NITI) that provide schemes for entrepreneurship and innovation, but the relevant information is scattered in various sections on their respective websites. Hence, an integrated platform linking the information and resources related to these schemes at one portal would facilitate awareness and information access and avoid confusion among potential entrepreneurs. Although there are research parks and startup hubs in various Indian universities/institutes, the link between academia and industry needs further strengthening. Rotatory internships or sabbaticals for academic faculty in an industry and vice versa could help to better understand mutual needs and strengthen linkages between the two sectors. This would also help the mentoring and networking processes, which would benefit student entrepreneurs by facilitating motivation, opportunity and skills. Ensuring funding especially at the creation stage of startups is critical to sustain the motivation of entrepreneurs and move the startup to the next stage. With various state governments and union territories of India creating fiscal and non-fiscal policies to encourage startups, there is an opportunity to leverage the state 
level initiatives to address the financing bottle neck at a regional level. This would also decrease the bureaucratic delays in federal/union funding which affects timeliness of funding. Funding along with mentorship and networking would play a critical role during the emerging phase of the startup. Finally, future startup policy directions should take into account India's huge informal sector, which has been less addressed by startups. Startups addressing the informal economy could fill this void for which social entrepreneurship needs to be nurtured through the startup ecosystem.

Although this study restricted itself to healthcare startups and India, the gaps emerging from the qualitative analysis cut across multiple sectors and are not unique to India. Existing global literature identify the vulnerability of startups even in normal times due to many of the issues identified above (Walsh and Cunningham, 2016; Stinchcombe, 1968, Kuckertz et al, 2020). Hence, based on the findings, a convergent stream framework (CSF) model (Figure 3) is proposed for global application, to understand the role and linkages among the multi-thematic areas of gaps across the lifecycle of startups, which could be used to identify and time the solutions. This model can be applied, tested, modified by researchers, practitioners and policy makers working in other countries and in different contexts to conceptualize the type, magnitude and location of gaps in the startup lifecycle in order to plan or implement suitable recommendations. 
Time
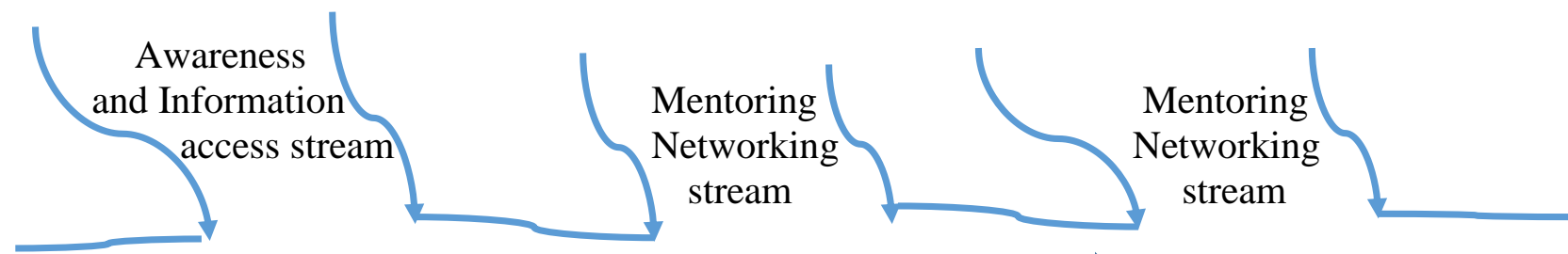

Start-ups (Creation)

(Emergence)

(Diffusion/Disruption)
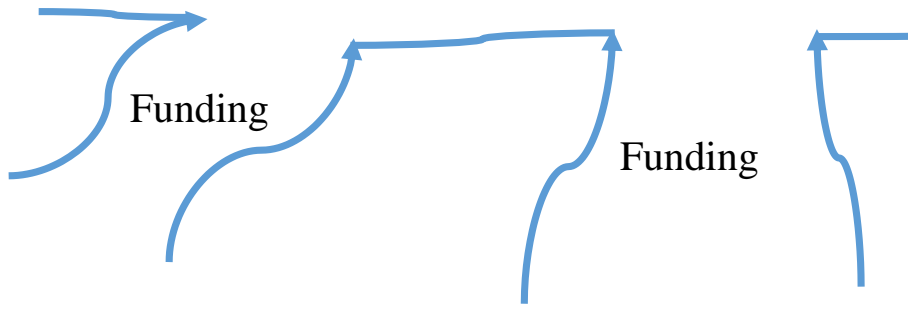

In this CSF model, startups can be considered like a large stream flowing across changing time and contexts. The three stages of startups-creation, emergence and diffusion/disruption are different parts of the same stream and reflect the evolution of startups. The multiple thematic gap areas are the multiple smaller streams, which converge with the flow into this large stream at different points. The nature of these streams (gap areas), their size and point of convergences with the life cycle stage would vary across different contextual realities and time. Figure 3 represents the application of this conceptual model based on the findings of this study, which reflects the current Indian startup scenario.

\section{Conclusions}

The startup policy in India initiated in 2016 has made significant contributions to the economy and healthcare sector, but there are gaps and scope for improvement. Given the current global health crisis and its impact on the economy, the role of healthcare sector startups in addressing this crisis and responding to the 'new normal' is critical. The findings 
of this study although limited to healthcare startups and startup ecosystem in India finds resonance with literature on startups in other sectors and other parts of the world. The decline in venture capital across the world has affected startups and their growth is at risk (Kuckertz, 2020). However, the health of financial institutes is still stable and there is a significant shift in the direction of venture capital towards healthcare (GII, 2020). In this context, healthcare startups become a significant player in the post-pandemic situation worldwide and the convergent stream framework emerging from this study is conceived as a conceptualization tool with potential for global applicability.

Startups could be a useful leveraging tool for translating interdisciplinary learning into multisectoral action for improving health. It would also be a useful tool for health diplomacy and contribute towards building relationships at various levels and with different actors, which is particularly relevant in the context of the ongoing COVID-19 pandemic. Policy measures are critical not only to tide over the crisis but also for long term sustainable solutions. In this context, the role of Health Technology Assessment (HTA) for identifying responsible innovations (startups) in healthcare which contribute to efficient, equitable and quality healthcare systems is critical. Future research should try to answer whether the new startup policy initiatives emerging from this crisis addresses issues of universal healthcare coverage like affordability, accessibility and quality of healthcare; and whether the use of healthcare technology has decreased or increased the inequity in society. In an increasingly globalized world with no country isolated, the pandemic provides a universal policy space to convert a crisis into an opportunity by working towards a coherent, responsive and inclusive ecosystem for sustainable development goals. 


\section{References}

1. Awasthi, D., Kashyap, S.P and Yagnik, J. (2006). Entrepreneurial Manifestations: Present Trend and Changing Landscape in an Inter-Regional Context, New Delhi, Government of India, Ministry of Micro, Small and Medium Enterprises.

2. Bertelsmann Stiftung. (2018). The Indian social enterprise landscape- Innovation for an Inclusive Future. Available from: https://www.bertelsmann-stiftung.de/en/ourprojects/germany-and-asia/news/the-indian-social-enterprise-landscape/ [Accessed May 7, 2021]

3. Carree, M., and A. Roy Thurik (1998). Small Firms and Economic Growth in Europe. Atlantic Economic Journal, Vol. 26 No. 2. pp. 137-146. DOI: 10.1007/BF02299356

4. Carree, M., and A. Roy Thurik (2002), The Impact of Entrepreneurship on Economic Growth, in Zoltan Acs and David B. Audretsch (Ed.), International Handbook of Entrepreneurship Research, Boston/Dordrecht: Kluwer Academic Publishers.

5. Cornell University, INSEAD, and WIPO (2020). GII 2020. The Global Innovation Index 2020: Who Will Finance Innovation? Ithaca, Fontainebleau, and Geneva.

6. Deloitte (2021). 2021 Global healthcare outlook. Laying a foundation for the future. Available from:www.deloitte.com/healthcareoutlook [Accessed May 7, 2021]

7. McKinsey Quarterly (2010). The emerging market in healthcare innovation. Available from: https://healthcare.mckinsey.com/sites/default/files/776858_The_Emerging_Market_in _Health_Care_Innovation.pdf . [Accessed May 7, 2021].

8. Price Waterhouse Cooper (2018). Re imagining the possible in the Indian healthcare ecosystem with emerging technologies. Available from: https://www.pwc.in/assets/pdfs/publications/2018/reimagining-the-possible-in-theindian-healthcare-ecosystem-with-emerging-technologies.pdf. [Accessed May 7, 2021].

9. Reynolds, P.D., et.al. (2002). Global Entrepreneurship Monitor 2002 Executive Report. Available from:

file:///C:/Users/User/Downloads/2002_Reynolds_others_GlobalEntrepreneurshipMon itorGEM2002GLOBALREPORT.pdf [Accessed may 7, 2021]

10. Startup India. Ministry of Commerce and Industry. DPIIT. Government of India. https://www.startupindia.gov.in/ [Accessed on May 7, 2021]

11. GEM (2018). Global Entrepreneurship Monitor 2017-18: India Report. Available from: https://www.gemconsortium.org/report/global-entrepreneurship-monitor-indiareport-2017-18 [Accessed May 7, 2021] 
12. India Brand Equity Foundation (2021). Healthcare sector. Available from: https://www.ibef.org/industry/healthcare-india [Accessed May 7, 2021]

13. Kuckretz, A., Brandle, L., Gaudig, A. et al. (2020). Startups in times of crisis - A rapid response to the COVID-19 pandemic. Journal of Business Venturing Insights. 13, e00169. https://doi.org/10.1016/j.jbvi.2020.e00169

14. Mukherjee K. (2021). Integrating technology, innovation and policy: COVID-19 and HTA. Health Policy and Technology.10,16-20. https://doi.org/10.1016/j.hlpt.2021.01.003

15. NASSCOM. (2018). Indian startup ecosystem. Approaching escape velocity.

16. Science Policy Forum (2020). Available from: https://thesciencepolicyforum.org/

17. Smorodinskaya, N., Russell, M.G., Katukov, D., Still, K. (2017). Innovation Ecosystems vs. Innovation Systems in Terms of Collaboration and Co-creation of Value. Proceedings of the 50th Hawaii International Conference on System Sciences, 5245-5254.

18. Soni (2019). Healthcare Landscape of India: The State Of India's Healthtech. Available from: https://inc42.com/features/healthtech-startups-landscape-india/ [Accessed May 7, 2021]

19. Stasha, S. (2021). The state of healthcare industry-statistics for 2021. Available from : https://policyadvice.net/insurance/insights/healthcare-statistics/ [Accessed May 7, 2021].

20. Stinchcombe, A.L.(1968). Social structure and organizations. Adv. Strat. Manag. 17, 229-259.

21. UNFPA (2017). India Aging Report. Available from: https://india.unfpa.org/sites/default/files/pub-pdf/India\%20Ageing\%20Report\%20\%202017\%20\%28Final\%20Version\%29.pdf [Accessed may 7, 2021]

22. Walsh, G.S., Cunningham, J.A. (2016). Business failure and entrepreneurship: emergence, evolution and future research. Found. Trends in Entrepren. 12, 163-285.

23. World Economic Forum, (2015). The Global Competitiveness Report 2015-2016, World Economic Forum, Geneva. 